\title{
AVALIAÇÃO DA QUALIDADE E ROTULAGEM DE PRODUTOS LÁCTEOS COMERCIALIZADOS NA CIDADE DE VENDA NOVA DO IMIGRANTE - ES ENTRE OS ANOS DE 2014 E 2015
}

\author{
QUALITY ASSESSMENT AND LABELING OF DAIRY PRODUCTS \\ COMMERCIALIZED IN THE CITY OF VENDA NOVA DO IMIGRANTE - ES \\ BETWEEN 2014 AND 2015
}

\author{
${ }^{1}$ Nayhume Jesus dos Santos \\ ${ }^{2}$ Lílian Caliman Baptisti \\ ${ }^{3}$ Bruna Garcia Filgueiras Azeredo \\ ${ }^{4}$ Sabrina Rohdt da Rosa \\ ${ }^{5}$ Danielle Cunha de Souza Pereira \\ ${ }^{6}$ Wilton Soares Cardoso \\ ${ }^{7}$ Maíra Maciel Mattos de Oliveira \\ ${ }^{8}$ Fabiana Carvalho Rodrigues \\ ${ }^{9}$ Flávia de Abreu Pinheiro*
}

\footnotetext{
${ }^{1}$ Instituto Federal do Espírito Santo - campus Venda Nova do Imigrante. E-mail: nayhsantos_@ hotmail.com

${ }^{2}$ Instituto Federal do Espírito Santo - campus Venda Nova do Imigrante. E-mail: liliancbaptisti@gmail.com

${ }^{3}$ Instituto Federal do Espírito Santo - campus Venda Nova do Imigrante. E-mail: bruna_filgueiras@hotmail.com

${ }^{4}$ Instituto Federal do Espírito Santo - campus Itapina. E-mail: sabrina.rosa@ifes.edu.br

${ }^{5}$ Instituto Federal do Espírito Santo - campus Venda Nova do Imigrante. E-mail: dany.csp@ gmail.com

${ }^{6}$ Instituto Federal do Espírito Santo - campus Venda Nova do Imigrante. E-mail: wilton.cardoso@ifes.edu.br

${ }^{7}$ Instituto Federal do Espírito Santo - campus Venda Nova do Imigrante. E-mail: maira.oliveira@ifes.edu.br

${ }^{8}$ Instituto Federal do Espírito Santo - campus Venda Nova do Imigrante. E-mail: fabiana.rodrigues@ifes.edu.br

${ }^{9}$ Instituto Federal do Espírito Santo - campus Venda Nova do Imigrante. E-mail: flavia.pinheiro@ifes.edu.br

*Autor de correspondência
}

Artigo submetido em 15/05/2020, aceito em 14/08/2020 e publicado em 28/08/2020.

Resumo: O trabalho objetivou avaliar a qualidade físico-química, microbiológica e a rotulagem de produtos lácteos comercializados na cidade de Venda Nova do Imigrante - ES, no período de 2014 a 2015. Iogurtes e queijos produzidos por nove agroindústrias do estado foram adquiridos no comércio local, totalizando 24 produtos, sendo 13 iogurtes e 11 queijos. Para caracterização físico-química foram realizadas análises de teor de água, $\mathrm{pH}$, atividade de água, acidez titulável, cinzas, proteínas, lipídeos e cloreto de sódio. Para caracterização microbiológica foram realizadas análises de contagem de microrganismos psicrotróficos, fungo filamentosos e leveduras, coliformes a $30{ }^{\circ} \mathrm{C}$ e $45^{\circ} \mathrm{C}$ e bactérias láticas. As informações contidas nos rótulos foram avaliadas segundo a legislação brasileira vigente. Os resultados das análises físico-químicas e microbiológicas revelaram a presença de amostras (iogurte e queijo, de diferentes marcas) em desacordo com a legislação vigente para pelo menos um dos parâmetros analisados, indicando falta de padronização e possíveis falhas no controle da qualidade higiênico-sanitária dos produtos. Quanto aos requisitos estabelecidos pela legislação brasileira para rotulagem, em geral, a maioria dos itens avaliados foi atendida pelos fabricantes das amostras de iogurtes e queijos estudadas. No entanto, destaca-se a necessidade de adequação quanto às 
informações corretas sobre aditivos e lista de ingredientes, e o uso de caracteres legíveis para todas as informações da rotulagem. Os resultados indicam a necessidade de uma constante e efetiva fiscalização dos produtos, para que alimentos em desacordo com a legislação não cheguem ao mercado consumidor.

Palavras-chave: iogurtes; queijos; legislação; segurança alimentar.

Abstract: This study aimed to evaluate the physicochemical, microbiological quality and labeling of dairy products commercialized in the city of Venda Nova do Imigrante - ES, in the period from 2014 to 2015. Yogurts and cheeses produced by nine agro-industries from the state were purchased from local stores, totaling 24 products, being 13 yogurts and 11 cheeses. For physicochemical characterization, analyzes of water content, $\mathrm{pH}$, water activity, total titratable acidity, ashes, proteins, lipids and sodium chloride were performed. For microbiological characterization, analyzes of psychrotrophic microorganisms count, filamentous fungus and yeasts, coliforms at $30^{\circ} \mathrm{C}$ and $45{ }^{\circ} \mathrm{C}$ and lactic bacteria were performed. The information contained on the labels was evaluated according to the current Brazilian legislation. The results of the physicochemical and microbiological analyzes revealed the presence of samples (yogurt and cheese, of different brands) in disagreement with the legislation for at least one of the analyzed parameters, indicating a lack of standardization and possible failures in the control of hygienic-sanitary quality of products. Regarding the requirements established by the Brazilian legislation for labeling, in general, most of the items evaluated were met by the manufacturers of the studied yogurt and cheese samples. However, stands out the need for adequacy regarding the correct information on additives and list of ingredients, and the use of legible characters for all labeling information. The results indicate the need for a constant and effective inspection of the products so that foods that do not comply with the legislation do not reach the consumer market.

Keywords: yogurts; cheeses; legislation; food safety.

\section{INTRODUÇÃO}

O leite é uma das commodities agropecuárias mais valiosas do mundo e todos os dias, bilhões de pessoas consomem leite, nas suas mais diversas formas (GDP, 2017). Dentre os produtos lácteos mais consumidos no mundo destacam-se os lácteos frescos (inclui leite fluido, iogurte, etc.), manteiga, queijos e leite em pó (EMBRAPA, 2019).

No Brasil, a indústria de laticínios é o segundo segmento mais importante da indústria de alimentos, estando atrás apenas do setor de derivados da carne (ABIA, 2018) o que caracteriza o leite e seus derivados como alimentos de relevância nutricional, social e econômica. Em 2018, o consumo aparente per capita no Brasil foi de 166,4 L/hab., sendo o leite longa vida (UHT) o produto lácteo mais consumido no país (EMBRAPA, 2019).

Apesar de não se configurar como o produto mais consumido, nos últimos anos os queijos têm apresentado taxas de crescimento de vendas maiores aos do leite UHT, possivelmente impulsionado pelo aumento do poder aquisitivo (SEBRAE, 2014) e maior procura por alimento de valor agregado. Enquanto o valor de vendas de leite UHT cresceu $138 \%$ entre 2005 e 2016, o valor de vendas do agregado dos queijos expandiu-se 509\%, ultrapassando as vendas de leite longa vida (EMBRAPA, 2019).

Além dos queijos, outros produtos de valor agregado são os iogurtes. O mercado de iogurtes no Brasil cresceu consideravelmente devido à incorporação de novos sabores e ingredientes à sua formulação; e devido à busca por uma alimentação mais saudável (KLEIN; FASSINA, 2015). Dessa forma, o controle da qualidade nutricional, físico-química e microbiológica dos alimentos é essencial para a saúde da população.

As doenças de origem alimentar (DTA) ocasionadas pela presença de 
microrganismos patogênicos podem causar sérios agravos à saúde do consumidor podendo em casos mais graves levar ao óbito. A presença de tais microrganismos patogênicos, a exemplo da Escherichia coli sp. indica deficiência nos procedimentos de higiene durante o processamento ou nas etapas pós-produção. Nestas condições, muitos iogurtes e queijos podem estar em desacordo com o Regulamento Técnico de Identidade e Qualidade de Leites Fermentados, Instrução Normativa $n .^{\circ}$ 46/2007 (BRASIL, 2007) e Regulamento Técnico de Identidade e Qualidade de Queijos, Portaria n. ${ }^{\circ}$ 146/1996 (BRASIL, 1996), ou podem ser classificados com impróprios ao consumo humano, com base nos padrões microbiológicos vigentes na Resolução RDC n. ${ }^{\circ}$ 12/2001 (BRASIL, 2001), devendo ser descartados, para não se tornarem problema de saúde pública.

Além da garantia dos aspectos de qualidade do produto, a conformidade das informações da rotulagem é obrigatória para todos "[...] alimentos, produzidos e comercializados, qualquer que seja sua origem, embalados na ausência do cliente e prontos para serem oferecidos aos consumidores" (BRASIL, 2003a). É por meio do rótulo que, ao adquirir um produto industrializado, o consumidor pode comparar marcas, verificar a relação entre a qualidade e o preço e, por motivos de saúde, evitar ou reduzir certos ingredientes, portanto, é necessária a atuação constante do Serviço de Inspeção (TAVARES et al. 2003).

Por determinação da legislação vigente, o rótulo deve ser fiel ao produto que o contém e ser escrito de forma legível para evitar a indução do consumidor a erros ou dúvidas, havendo, ainda, a obrigação de se mencionar no rótulo as seguintes informações: denominação de venda, lista de ingredientes com seus respectivos aditivos alimentares, conteúdo líquido, identificação da origem, lote, data de fabricação, prazo de validade, razão social, endereço, instruções sobre o preparo e uso do alimento, quando necessário (BRASIL, 2002a), além da presença da frase "contém Glúten" ou "não contém Glúten", conforme o caso (BRASIL, 2003b).

Com base nestes pressupostos, este trabalho teve por objetivo avaliar a qualidade físico-química, microbiológica e as informações contidas nos rótulos das embalagens de iogurtes e queijos comercializados na cidade de Venda Nova do Imigrante - ES, visando observar o cumprimento à legislação pelas agroindústrias alimentícias que os produzem.

\section{MATERIAL E MÉTODOS}

\subsection{AMOSTRAS}

Iogurtes e queijos produzidos por nove agroindústrias localizadas no estado do Espírito Santo foram adquiridos no comércio local da cidade de Venda Nova do Imigrante - ES no período de setembro de 2014 a maio de 2015. Adquiriu-se de forma aleatória 13 amostras de iogurtes (sabores morango, ameixa e pêssego) e 11 amostras de queijos (tipo Minas Frescal Minas Padrão e muçarela) num total de 24 amostras. Todos os produtos estavam acondicionados em embalagens plásticas, em bom estado de conservação, no prazo de validade, e dispostas em expositores refrigerados nos pontos de venda. Não foi avaliada a temperatura no momento da coleta. As amostras foram transportadas em caixas de isopor (previamente sanitizadas com álcool 70\%) e mantidas sob refrigeração, por período máximo de 8 $\mathrm{h}$, até o momento das análises.

As nove diferentes marcas, fabricantes de iogurte e queijos, foram numeradas e codificadas com as letras "A" à "I".

\subsection{ANÁLISES FÍSICO-QUÍMICAS}


As análises foram realizadas nos Laboratórios de Análises de Alimentos e Microbiologia do Instituto Federal do Espírito Santo, IFES, campus Venda Nova do Imigrante.

Os iogurtes e queijos foram analisados quanto ao teor de água (umidade), $\mathrm{pH}$, atividade de água $\left(\mathrm{a}_{\mathrm{w}}\right)$, acidez total titulável (\% ácido láctico), cinzas, proteínas, lipídeos e cloreto de sódio - $\mathrm{NaCl}$ (para as amostras queijos), de acordo com a metodologia oficial descrita pelo Ministério da Agricultura Pecuária e Abastecimento (BRASIL, 2006) e as Normas Analíticas do Instituto Adolfo Lutz (IAL, 2008).

\subsection{ANÁLISES MICROBIOLÓGICAS}

As embalagens de iogurtes e queijos foram desinfetadas com álcool $70 \%$. De forma representativa, $25 \mathrm{~g}$ de cada amostra foram homogeneizadas em embalagens estéreis juntamente com 225 $\mathrm{mL}$ de água peptonada $0,1 \%$ estéril (diluição $10^{-1}$ ). A partir desta, foram feitas sucessivas diluições decimais, tantas quanto necessárias, conforme os métodos preconizados pela Food and Drug Administration (FDA) descrito e adaptado por da Silva et al. (2010) para detecção de microrganismos psicrotróficos, fungo filamentosos e leveduras, coliformes a 30 ${ }^{\circ} \mathrm{C}$ e $45^{\circ} \mathrm{C}$ e bactérias láticas.

\subsection{ANÁLISE DA ROTULAGEM}

As informações contidas nos rótulos dos iogurtes e queijos foram avaliadas segundo a legislação brasileira vigente. Desta forma, foram adotados os critérios do Decreto Lei n. ${ }^{\circ}$ 986, de 21 de outubro de 1969 (BRASIL, 1969), que institui Normas básicas sobre alimentos; da Lei n. ${ }^{\circ}$ 8.078, de 11 de setembro de 1990 (BRASIL, 1990), que estabelece Normas de Proteção e Defesa do Consumidor; da Portaria INMETRO n. ${ }^{\circ}$ 157, de 19 de agosto de 2002 (BRASIL, 2002b), que aprova o Regulamento Técnico Metrológico estabelecendo a forma de expressar o conteúdo líquido a ser utilizado nos produtos pré-medidos; da Resolução RDC ANVISA n. ${ }^{\circ} 259$, de 20 de setembro de 2002 (BRASIL, 2002a), a qual aprova o regulamento técnico sobre Rotulagem de Alimentos Embalados; da Resolução RDC ANVISA n. ${ }^{\circ} 360$, de 23 de dezembro de 2003 (BRASIL, 2003a), que determina a Rotulagem Nutricional de Alimentos Embalados; da Resolução RDC ANVISA n. $^{\circ}$ 359, de 23 de dezembro de 2003 (BRASIL, 2003c), que estabelece as Porções de Alimentos Embalados para Fins de Rotulagem Nutricional; e Instrução Normativa n. ${ }^{\circ}$ 22/2005 (BRASIL, 2005), que regulamenta a Rotulagem de Produto de Origem Animal Embalado.

\subsection{ANÁLISE DOS DADOS}

Os resultados das análises físicoquímicas de iogurtes e queijos foram analisados de acordo com o Regulamento Técnico de Identidade e Qualidade de Leites Fermentados, Instrução Normativa n. ${ }^{\circ}$ 46/2007 (BRASIL, 2007), Regulamento Técnico de Identidade e Qualidade de Queijos, Portaria n. ${ }^{\circ}$ 146/1996 (BRASIL, 1996) alterado pela Instrução Normativa n. ${ }^{\circ}$ 4/2004 (BRASIL, 2004) e Regulamento Técnico de Identidade e Qualidade de Queijo Mozzarella, Portaria $n^{\circ}$ 364/1997 (BRASIL, 1997) alterado pela Portaria n. ${ }^{\circ}$ 837/2018 (BRASIL, 2018).

As análises microbiológicas foram analisadas de acordo com a Resolução RDC n. ${ }^{\circ}$ 12/2001 (BRASIL, 2001). As amostras que corresponderam ao limite estabelecido de acordo com o tipo de alimento foram consideradas próprias para o consumo humano e classificadas como "Aceitáveis", as demais foram consideradas como impróprias ao consumo humano e classificadas como "Inaceitáveis".

Os dados obtidos através das análises físico-químicas, microbiológicas e 
rotulagem foram avaliados utilizando-se análise descritiva, sendo expressos como média, desvio-padrão e porcentagem, sempre que necessário. As análises foram realizadas em triplicata com duas repetições e seus dados foram dispostos em tabelas.

\section{RESULTADOS E DISCUSSÃO}

\subsection{ANÁLISES FÍSICO-QUÍMICAS}

Os dados referentes às avaliações físico-químicas dos iogurtes e queijos são apresentados nas Tabelas 1 e 2, respectivamente.

Segundo Cecchi (2003) a umidade de um alimento está relacionada com sua estabilidade, qualidade e composição e pode afetar o armazenamento, a embalagem e o processamento. Para os iogurtes, pode-se observar que a umidade das amostras variou de $76,10 \%$ a $80,47 \%$ (Tabela 1). Para Cecchi (2003) o teor de umidade em produtos lácteos fluidos pode variar de $87 \%$ a $91 \%$, logo, todos os iogurtes analisados apresentaram teor de água inferior ao esperado, o que pode indicar maior teor de sólidos totais nas amostras. Conforme a Tabela Brasileira de Composição dos Alimentos (TACO, 2011) o teor médio de água (umidade) em iogurtes sabor morango e pêssego corresponde a $85 \%$, assim como a relatada por Martins et al. (2013) ao analisar iogurte de soja suplementado com inulina. Para atividade de água $\left(\mathrm{a}_{\mathrm{w}}\right)$, os valores obtidos variaram de 0,97 a 0,98 (Tabela 1 ) o que indica semelhança entre as amostras analisadas. Estes resultados foram também semelhantes aos relatados por dos Santos et al. (2016) na avaliação de iogurte natural fresco $(0,987)$ e reidratado após liofilização $(0,983)$. Munhoz et al. (2019) obtiveram valores de atividade de água entre $0,951 \pm 0,001$ e $0,954 \pm 0,012$ para diferentes formulações de iogurte de açaí. Vale destacar que, a atividade de água refere-se à água disponível ("água livre”) no alimento, podendo variar conforme os ingredientes adicionados na formulação.

Os valores de $\mathrm{pH}$ variaram de 3,90 a 4,69. Já o teor de acidez variou de $0,77 \%$ a $1,0 \%$ (Tabela 1). Todas as amostras estavam de acordo com o limite de acidez estabelecido pela legislação (BRASIL, 2007), cujo limite é entre 0,6 e $1,5 \%$. Silva et al. (2012) encontraram para iogurtes valores de $\mathrm{pH}$ variando de 3,57 a 4,03 e acidez de $0,75 \%$ a $1,08 \%$, valores semelhantes ao presente estudo, evidenciando a normalidade das reações de fermentação.

Tabela 1: Média e desvio-padrão dos dados obtidos nas análises físico-químicas de iogurtes comercializados no município de Venda Nova do Imigrante - ES

\begin{tabular}{cccccccc}
\hline $\begin{array}{c}\text { Sabor }^{1}{ }^{\mathbf{2}} \\
\text { Marca }^{2}\end{array}$ & $\begin{array}{c}\text { Teor de água } \\
(\boldsymbol{\%})\end{array}$ & $\mathbf{a}_{\mathbf{w}}$ & $\mathbf{p H}$ & Acidez (\%) & Cinzas (\%) & Proteína (\%) & Lipídeos (\%) \\
\hline MA & $78,62 \pm 0,34$ & $0,98 \pm 0,00$ & $4,00 \pm 0,17$ & $0,83 \pm 0,08$ & $0,70 \pm 0,06$ & $7,3 \pm 0,1$ & $6,6 \pm 0,4$ \\
MB & $79,53 \pm 0,61$ & $0,97 \pm 0,00$ & $4,01 \pm 0,09$ & $0,80 \pm 0,02$ & $0,65 \pm 0,02$ & $8,2 \pm 0,1$ & $6,5 \pm 0,2$ \\
MC & $80,47 \pm 0,17$ & $0,98 \pm 0,00$ & $3,92 \pm 0,06$ & $0,80 \pm 0,15$ & $0,69 \pm 0,04$ & $6,8 \pm 0,2$ & $6,4 \pm 0,5$ \\
MG & $78,79 \pm 0,11$ & $0,98 \pm 0,01$ & $4,69 \pm 0,77$ & $0,92 \pm 0,01$ & $0,65 \pm 0,01$ & $4,7 \pm 0,6$ & $2,7 \pm 0,9$ \\
MI & $78,30 \pm 0,41$ & $0,98 \pm 0,00$ & $3,93 \pm 0,10$ & $0,94 \pm 0,03$ & $0,68 \pm 0,02$ & $6,0 \pm 0,2$ & $3,4 \pm 0,4$ \\
\hline AA & $77,12 \pm 0,93$ & $0,97 \pm 0,00$ & $4,07 \pm 0,19$ & $0,90 \pm 0,02$ & $0,75 \pm 0,08$ & $8,0 \pm 0,4$ & $8,0 \pm 0,3$ \\
AB & $80,29 \pm 0,56$ & $0,97 \pm 0,00$ & $4,09 \pm 0,13$ & $0,84 \pm 0,02$ & $0,67 \pm 0,02$ & $8,6 \pm 0,2$ & $7,6 \pm 0,2$
\end{tabular}




\begin{tabular}{cccccccc} 
AC & $80,39 \pm 0,31$ & $0,98 \pm 0,01$ & $4,17 \pm 0,05$ & $0,77 \pm 0,07$ & $0,66 \pm 0,02$ & $6,8 \pm 0,1$ & $7,1 \pm 0,3$ \\
AG & $77,03 \pm 1,84$ & $0,98 \pm 0,00$ & $4,00 \pm 0,16$ & $0,88 \pm 0,07$ & $0,67 \pm 0,01$ & $6,9 \pm 0,1$ & $5,4 \pm 0,1$ \\
AI & $76,57 \pm 1,34$ & $0,97 \pm 0,00$ & $3,90 \pm 0,03$ & $1,00 \pm 0,10$ & $0,70 \pm 0,04$ & $6,9 \pm 0,5$ & $3,8 \pm 0,3$ \\
\hline PC & $80,15 \pm 0,13$ & $0,98 \pm 0,01$ & $4,01 \pm 0,19$ & $0,83 \pm 0,01$ & $0,66 \pm 0,01$ & $4,8 \pm 0,4$ & $3,3 \pm 0,8$ \\
PG & $78,45 \pm 0,65$ & $0,98 \pm 0,00$ & $4,01 \pm 0,17$ & $0,95 \pm 0,04$ & $0,68 \pm 0,04$ & $5,7 \pm 0,5$ & $4,0 \pm 0,3$ \\
PI & $76,10 \pm 1,02$ & $0,97 \pm 0,00$ & $4,03 \pm 0,08$ & $0,88 \pm 0,07$ & $0,63 \pm 0,01$ & $6,0 \pm 0,2$ & $2,4 \pm 0,6$ \\
\hline Padrão & & & & $0,6 \%$ e & Padrão não & $2,9 \%$ & $3,0 \%$ a $5,9 \%$ \\
\hline
\end{tabular}

Fonte: Autoria própria. ${ }^{1}$ Sabores dos iogurtes analisados - M: Morango, A: Ameixa e P: Pêssego. ${ }^{2}$ Marcas dos produtos - identificação da agroindústria (A, B, C, G e I). ${ }^{3}$ Refere-se ao padrão da legislação (BRASIL, 2007).

O teor de cinzas de um alimento representa o conteúdo mineral, resíduo inorgânico, que permanece após a queima de matéria orgânica de uma amostra (CECCHI, 2003). Os iogurtes apresentaram teor de cinzas variando de $0,63 \%$ a $0,75 \%$ (Tabela 1). A Tabela TACO (2011) descreve para iogurtes sabor morango e pêssego teor de cinzas de $0,6 \%$, valor semelhante ao relatado no presente estudo. Martins et al. (2013) ao analisar iogurte de soja suplementado com inulina encontraram menor valor de cinzas $(0,48 \%)$ o que difere do presente estudo. O cálcio é o mineral em maior quantidade presente em iogurtes, entretanto outros minerais também estão presentes em sua composição, a exemplo do magnésio, fósforo e zinco (FUENTE et al., 2003).

Para proteína e lipídeos, os dados obtidos variaram de $4,7 \%$ a $8,6 \%$ e de $2,4 \%$ a $8,0 \%$, respectivamente (Tabela 1 ). Valores menores foram relatados na Tabela TACO (2011) para iogurte sabor morango e pêssego, 2,5\% a $2,7 \%$ e $2,3 \%$ respectivamente, e por Martins et al. (2013) ao analisar iogurte de soja suplementado com inulina, 3,64\% e 1,73\%, respectivamente. A Instrução Normativa n. ${ }^{\circ}$ 46/2007 (BRASIL, 2007) determina que Leites Fermentados Integrais devem ter teor mínimo de proteínas lácteas de $2,9 \%$ e matéria gorda láctea de 3,0\% a $5,9 \%$, assim, as amostras (MA, AA, MB,
$\mathrm{AB}, \mathrm{MC}, \mathrm{AC}, \mathrm{MG}$ e PI) de iogurtes das marcas A, B, C, G e I estavam em desacordo com o Regulamento Técnico em relação ao teor de lipídeos (Tabela 1), correspondendo a $61,54 \%$ das amostras de iogurte.

Para os queijos analisados foram encontrados teores de umidade variando de $52,39 \%$ a $58,47 \%$ para queijos Minas Frescal; $41,20 \%$ a $49,83 \%$ para queijos Minas Padrão; e 41,26\% a 46,95\% para muçarela (Tabela 2). A legislação brasileira estabelece umidade mínima de 55\% para queijo Minas Frescal, entre 46\% e $54,9 \%$ para queijo Minas Padrão (BRASIL, 1996; BRASIL, 2004) e máxima de $60 \%$ para queijo muçarela (BRASIL, 1997), dessa forma uma amostra de queijo Minas Frescal $(33,33 \%$ em relação a esse tipo de queijo) e duas amostras de queijo Minas Padrão (40\% em relação a esse tipo de queijo) estavam em desacordo com a legislação (Tabela 2). Dias et al. (2016) ao analisar queijos Minas Frescal encontraram teores de umidade superior a $55 \%$, caracterizando-as como queijos de muito alta umidade, conforme previsto na Instrução Normativa $n^{\circ} 4 / 2004$ (BRASIL 2004).

Os queijos Minas Frescal apresentaram maior atividade de água $\left(\mathrm{a}_{\mathrm{w}}\right)$ $(0,98)$, seguido dos queijos Minas Padrão $(0,96$ a 0,97$)$ e queijos muçarela $(0,95$ a 0,97) (Tabela 2). Em estudo realizado por 
De Souza et al. (2017), os autores descreveram valor médio de $\mathrm{a}_{\mathrm{w}}$ de $0,963 \pm$ 0,016 para queijo Minas frescal comercializado na Zona da Mata Mineira, sendo inferior ao encontrado no presente estudo para o mesmo tipo de queijo. De Sousa et al. (2014) relataram valores de $a_{w}$ variando entre 0,89 a 0,96 para queijo tipo coalho comercializado em seis estados da região nordeste. A variação de $\mathrm{a}_{\mathrm{w}}$, para diferentes tipos de queijos, pode ser relacionada ao processamento (por exemplo, prensagem e maturação), teores de sal e água. Assim, queijos maturados tendem a apresentar menor valor de $a_{w}$ que queijos frescos com alto teor de umidade.

Os valores de $\mathrm{pH}$ e acidez são adotados na produção queijeira para realizar um controle durante seu processamento e armazenamento (DIAS et al., 2016). Os valores de $\mathrm{pH}$ variaram de 5,67 a 6,61 para queijos Minas Frescal, 4,87 a 5,90 para queijos Minas Padrão e, 5,12 a 5,46 para queijos muçarela. $\mathrm{O}$ teor de acidez variou de $0,18 \%$ a $0,49 \%$, para queijos Minas Frescal, 0,12\% a 0,63\%, para queijos Minas Padrão e, 0,40\% a $0,44 \%$, para queijos muçarela (Tabela 2). Variações de $\mathrm{pH}$ e acidez em um mesmo tipo de queijo podem estar relacionadas com as características da matéria-prima, métodos empregados durante o processamento, tempo e temperatura de armazenamento nos expositores dos supermercados. Dias et al. (2016) encontraram valores semelhantes de $\mathrm{pH}$ $(4,3 \%$ a 6,7$)$ e acidez $(0,10 \%$ a 0,68$)$ ao analisar queijos Minas Frescal.
Quanto ao teor de cinzas, pode-se observar que os resultados variaram de $2,67 \%$ a 3,58\% para queijo Minas Frescal, $3,20 \%$ a $4,63 \%$ para Minas Padrão e, $2,88 \%$ a $4,46 \%$ para queijos muçarela (Tabela 2), valores semelhantes aos descritos pela Tabela TACO (2011) para queijo Minas Frescal (3,0\%), Minas Padrão $(3,5 \%)$ e muçarela $(3,8 \%)$. A quantidade de cloreto de sódio presente em uma amostra de queijo depende principalmente do teor de água e do processo de salga utilizado. Os valores médios para $\mathrm{NaCl}$ variaram de $0,40 \%$ a $1,23 \%$ para queijos Minas Frescal, $0,54 \%$ a $1,42 \%$ para queijos Minas Padrão e, $0,25 \%$ a $1,61 \%$ para queijos muçarela (Tabela 2). Valores semelhantes aos encontrados por Dias et al. (2016) ao analisar queijos Minas Frescal $(0,7 \%$ a 1,4\%). Arruda et al. (2010) encontraram valores de $\mathrm{NaCl}$ superiores ao relatado no presente estudo, variando de $0,58 \%$ a 2,96\% para os queijos Minas Frescal e de $0,96 \%$ a $7,04 \%$, para queijos Minas Padrão. Queijos fabricados sem maiores conhecimentos tecnológicos poderão apresentar concentrações variadas de sal, desde quantidades pequenas, conforme observado no presente estudo, até níveis muito elevados, conforme observado por Arruda et al. (2010), levando-se à despadronização do produto. Além disso, o excesso de sal prejudica a qualidade sensorial do queijo, e pode denotar falha no processamento ou a tentativa de mascarar algum defeito como o sabor amargo (ARRUDA et al., 2010).

Tabela 2: Média e desvio-padrão dos dados obtidos nas análises físico-químicas de queijos comercializados no município de Venda Nova do Imigrante - ES

\begin{tabular}{ccccccccc}
\hline $\begin{array}{c}\text { Tipo de } \\
\text { produto }^{1} / \\
\text { Marca }^{2}\end{array}$ & $\begin{array}{c}\text { Teor de água } \\
(\%)\end{array}$ & $\mathbf{a}_{\mathbf{w}}$ & $\mathbf{p H}$ & Acidez (\%) & Cinzas (\%) & NaCl (\%) & Proteína (\%) & $\begin{array}{c}\text { Lipídeos } \\
(\%)\end{array}$ \\
\hline FA & $58,47 \pm 0,20$ & $0,98 \pm 0,00$ & $6,61 \pm 0,01$ & $0,18 \pm 0,02$ & $2,67 \pm 0,27$ & $0,40 \pm 0,08$ & $17,8 \pm 0,7$ & $24,0 \pm 1,4$ \\
FC & $55,30 \pm 1,29$ & $0,98 \pm 0,01$ & $5,97 \pm 0,68$ & $0,19 \pm 0,02$ & $3,58 \pm 0,36$ & $1,23 \pm 0,09$ & $18,4 \pm 0,5$ & $25,5 \pm 1,7$ \\
FG & $52,39 \pm 1,51$ & $0,98 \pm 0,00$ & $5,67 \pm 0,16$ & $0,49 \pm 0,09$ & $2,90 \pm 0,30$ & $0,50 \pm 0,09$ & $20,2 \pm 1,3$ & $25,8 \pm 2,5$ \\
\hline
\end{tabular}




\begin{tabular}{ccccccccc}
\hline PA & $49,07 \pm 1,42$ & $0,97 \pm 0,00$ & $5,90 \pm 0,15$ & $0,12 \pm 0,01$ & $4,34 \pm 0,47$ & $1,41 \pm 0,46$ & $21,9 \pm 0,5$ & $29,0 \pm 1,2$ \\
PB & $42,77 \pm 0,57$ & $0,96 \pm 0,01$ & $5,47 \pm 0,32$ & $0,32 \pm 0,03$ & $4,63 \pm 0,64$ & $1,42 \pm 0,37$ & $22,6 \pm 1,0$ & $27,0 \pm 0,8$ \\
PD & $46,32 \pm 0,48$ & $0,97 \pm 0,00$ & $5,05 \pm 0,27$ & $0,53 \pm 0,00$ & $3,20 \pm 0,18$ & $0,78 \pm 0,05$ & $20,9 \pm 0,8$ & $26,8 \pm 1,5$ \\
PG & $41,20 \pm 0,88$ & $0,97 \pm 0,00$ & $5,40 \pm 0,21$ & $0,57 \pm 0,02$ & $3,82 \pm 0,15$ & $0,54 \pm 0,09$ & $26,9 \pm 2,3$ & $27,0 \pm 3,6$ \\
PH & $49,83 \pm 0,37$ & $0,97 \pm 0,00$ & $4,87 \pm 0,39$ & $0,63 \pm 0,08$ & $3,32 \pm 0,79$ & $0,90 \pm 0,09$ & $20,6 \pm 1,4$ & $26,8 \pm 1,0$ \\
\hline ME & $42,25 \pm 1,73$ & $0,95 \pm 0,01$ & $5,46 \pm 0,32$ & $0,41 \pm 0,03$ & $4,46 \pm 0,14$ & $1,61 \pm 0,07$ & $28,0 \pm 1,2$ & $23,3 \pm 1,7$ \\
MF & $41,26 \pm 0,94$ & $0,95 \pm 0,01$ & $5,35 \pm 0,09$ & $0,40 \pm 0,05$ & $4,43 \pm 0,39$ & $1,33 \pm 0,02$ & $26,0 \pm 0,2$ & $24,5 \pm 0,7$ \\
MG & $46,95 \pm 1,34$ & $0,97 \pm 0,00$ & $5,12 \pm 0,39$ & $0,44 \pm 0,00$ & $2,88 \pm 0,22$ & $0,25 \pm 0,09$ & $26,0 \pm 0,4$ & $24,3 \pm 0,4$ \\
\hline
\end{tabular}

Padrão ${ }^{3}$

Umidade: Mín. 55\% Minas Frescal, 46\% a 54,9\% Minas Padrão e Máx. 60\% muçarela. Conteúdo de matéria gorda: Gordos: 45,0 a 59,9\%, Semigordo: 25,0 a 44,9\% e Magros: 10,0 a 24,9\%. Demais parâmetro: padrões não estabelecidos

Fonte: Autoria própria. ${ }^{1}$ Tipos de queijos analisados - F: Minas Frescal, P: Minas Padrão, M: Muçarela. ${ }^{2}$ Marcas dos produtos - identificação da agroindústria (A, B, C, D, E, F, G e H). ${ }^{3}$ Refere-se ao padrão da legislação (BRASIL, 1996; BRASIL, 1997; BRASIL, 2004).

Para proteína, os dados obtidos variaram de $17,8 \%$ a $20,2 \%$ para queijo Minas Frescal, 20,6\% a 26,9\% para Minas Padrão e, $26,0 \%$ a $28,0 \%$ para queijo muçarela (Tabela 2), valores semelhantes aos descritos na Tabela TACO (2011) para queijo Minas Frescal $(17,4 \%)$ Minas Padrão $(21,2 \%)$ e muçarela $(22,6 \%)$. Conforme esperado, Cunha et al. (2002) encontraram valores superiores de proteína ao analisar queijos Minas Frescal com baixo teor de gordura $(22,05 \%$ a $24,01 \%)$.

O teor de lipídeos variou de $24,0 \%$ a 25,8\% para queijo Minas Frescal, 26,8\% a 29,0\%, para queijo Minas Padrão e, $23,3 \%$ a $24,5 \%$ para queijo muçarela (Tabela 2), podendo ser classificados como magros $(10,0 \%$ a $24,9 \%)$ ou semigordos $(25,0 \%$ e $44,9 \%)$ (BRASIL, 1996). A Tabela TACO (2011) descreve valores inferiores de lipídeos para queijo Minas Frescal $(20,2 \%)$ e Minas Padrão $(24,6 \%)$ e superior para muçarela $(25,2 \%)$. Da Silva et al. (2012) e Furtado (2005) encontraram variação de lipídeos semelhante ao presente estudo para queijos Minas artesanais $(21,68 \%$ a $26,09 \%)$ e queijos Minas Padrão (23\% a 25\%) respectivamente. Já Castro et al. (2012) encontraram para queijo muçarela variação de $25,5 \%$ a $31,1 \%$, valor superior ao descrito na Tabela TACO (2011). Essas variações significativas em queijos no mercado podem estar relacionadas com as características da matéria-prima utilizada e teor de umidade do queijo final, o que indica a importância de seguir os Regulamentos Técnicos de Identidade e Qualidade e demais legislações existentes para assegurar as características físicoquímicas e sensoriais dos produtos finais.

\subsection{ANÁLISES MICROBIOLÓGICAS}

Os dados referentes às avaliações microbiológicas dos iogurtes e queijos são apresentados nas Tabelas 3 e 4, respectivamente. Para esse tipo de análise adotou-se expressar individualmente as médias dos dados da primeira e segunda repetições, lote 1 e lote 2 , respectivamente, visando comparar os resultados com a legislação vigente, visto que algumas amostras apresentaram um elevado desviopadrão. Tal fato não ocorreu nas análises físico-químicas.

A qualidade microbiológica de iogurtes e queijos depende inicialmente do 
grau de contaminação do leite utilizado em sua fabricação e da garantia dos métodos empregados em seu tratamento térmico.

Para as amostras de iogurte (Tabela 3 ), pode-se observar que para a contagem de bactérias psicrotróficas, com exceção da amostra sabor morango da marca A (MA) que apresentou contagem de $4,9 \times 10^{3}$ $\mathrm{UFC/g}$ (lote 1), todas as demais amostras apresentaram contagem inferior a $1,0 \times 10^{1}$ UFC/g (Tabela 3). Lima et al. (2014) e Ferreira et al. (2019) relataram contagens de bactérias psicrotróficas na ordem de $10^{2}$ a $10^{5} \mathrm{UFC} / \mathrm{g}$ nas amostras de iogurte analisadas. Os psicrotróficos são microrganismos muito importantes dentro do mercado lácteo nacional, esses microrganismos são capazes de se multiplicar em temperaturas de refrigeração, independentemente de sua temperatura ótima de crescimento. Apesar das legislações vigentes não possuírem padrões de crescimento para bactérias psicrotróficas no iogurte, estes microrganismos são considerados importantes indicadores de qualidade de alimentos. Segundo Jay (2005), a presença desses microrganismos também pode ser devido a deficiências nos processos de limpeza e sanitização dos equipamentos utilizados na fabricação destes alimentos.

Para a contagem de fungos filamentosos e leveduras, o limite máximo estabelecido pela Instrução Normativa $\mathrm{N}^{\circ}$

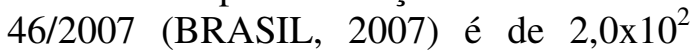
UFC/g (2,30 ciclos Log). Dentre os iogurtes analisados (lotes 1 e 2), foram encontradas variações nas populações de fungos filamentosos e leveduras de $<1,0 \times 10^{1} \mathrm{UFC} / \mathrm{g}$ a $1,7 \times 10^{7} \mathrm{UFC} / \mathrm{g}$ (Tabela 3). As amostras que se apresentaram aptas (aceitáveis) para consumo foram: $\mathrm{MB}$, MC, MI, AB, AG e AI (lote 1), e AC e PC (lote 2).
A elevada presença de fungos filamentosos e leveduras em iogurtes pode ser um indicativo de práticas sanitárias insatisfatórias, além da possível utilização de ingredientes com contaminação excessiva, a exemplos das polpas de frutas e açúcar. Segundo Tebaldi et al. (2007) alguns fungos filamentosos são produtores de micotoxinas, as quais podem afetar a saúde humana, não podendo ser encontrados em contagens elevadas em alimentos.

Vários estudos têm mostrado variações de população de fungos filamentosos e, ou leveduras em iogurtes: $0,1 \times 10^{1}$ a $2,7 \times 10^{3} \mathrm{UFC/g}$ (MOREIRA et al., 2001), $<1,0 \times 10^{1}$ a $8,86 \times 10^{1} \mathrm{UFC} / \mathrm{g}$ (EMILIANO et al., 2017) e $<1,0 \times 10^{1}$ a $5,6 \times 10^{4} \mathrm{UFC} / \mathrm{g}$ (RIBEIRO et al., 2016; OLIVEIRA et al., 2013). Para se evitar que essa contaminação ultrapasse o limite estipulado pela legislação, é necessário maior rigor, desde a seleção de matériasprimas de boa qualidade, até o cumprimento das medidas higiênicosanitárias previstas em lei.

Para coliformes a $30^{\circ} \mathrm{C}$ (coliformes totais) e coliformes a $45{ }^{\circ} \mathrm{C}$ (coliformes termotolerantes), a legislação brasileira permite máximo de $10^{2} \mathrm{NMP} / \mathrm{g}$ (2 ciclos Log) para coliformes a $30{ }^{\circ} \mathrm{C}$ (BRASIL, 2007) e máximo de $10^{1} \mathrm{NMP} / \mathrm{g}$ (1 ciclo Log) para coliformes a $45{ }^{\circ} \mathrm{C}$ (BRASIL, 2001; BRASIL, 2007). As amostras de iogurte sabor ameixa da marca A (AA), obtiveram contagens de coliformes a $30^{\circ} \mathrm{C}$ iguais a $>1,0 \times 10^{4} \mathrm{NMP} / \mathrm{g}$ e $1,1 \times 10^{3}$ $\mathrm{NMP} / \mathrm{g}$, respectivamente para os lotes $1 \mathrm{e}$ 2 , estando em desacordo com os padrões de qualidade preconizados na legislação. Para coliformes a $45^{\circ} \mathrm{C}$, apenas a amostra AA do lote 1 (43 NMP/g) não estava apta para consumo (Tabela 3 ).

Tabela 3: Média e desvio-padrão dos resultados das análises microbiológicas de iogurtes, comercializados no município de Venda Nova do Imigrante - ES 


\begin{tabular}{|c|c|c|c|c|c|c|}
\hline $\operatorname{marca}^{2}$ & Lote & $\begin{array}{l}\text { Psicrotróficos } \\
\text { (UFC/g) }\end{array}$ & $\begin{array}{l}\text { Fungos filamentosos } \\
\text { e leveduras (UFC/g) }\end{array}$ & $\begin{array}{c}\text { Coliformes } \\
\text { a } 30^{\circ} \mathrm{C}(\mathrm{NMP} / \mathrm{g})\end{array}$ & $\begin{array}{c}\text { Coliformes } \\
\text { a } 45^{\circ} \mathrm{C}(\mathrm{NMP} / \mathrm{g})\end{array}$ & $\begin{array}{c}\text { Bactérias lácticas } \\
\text { (UFC/g) }\end{array}$ \\
\hline \multirow{2}{*}{ MA } & 1 & $4,9 \times 10^{3}$ & $3,7 \times 10^{3}$ & $3,5 \times 10^{1}$ & 7,4 & $9,2 \times 10^{3}$ \\
\hline & 2 & $<1,0 \times 10^{1}$ & $4,0 \times 10^{3}$ & $<3,0$ & $<3,0$ & $9,1 \times 10^{4}$ \\
\hline \multirow{2}{*}{ MB } & 1 & $<1,0 \times 10^{1}$ & $<1,0 \times 10^{1}$ & $<3,0$ & $<3,0$ & $>1,0 \times 10^{4}$ \\
\hline & 2 & $<1,0 \times 10^{1}$ & $3,0 \times 10^{5}$ & $3,5 \times 10^{1}$ & $<3,0$ & $<1,0 \times 10^{1}$ \\
\hline \multirow{2}{*}{ MC } & 1 & $<1,0 \times 10^{1}$ & $<1,0 \times 10^{1}$ & $<3,0$ & $<3,0$ & $8,5 \times 10^{2}$ \\
\hline & 2 & $<1,0 \times 10^{1}$ & $6,5 \times 10^{5}$ & 6,2 & $<3,0$ & $<1,0 \times 10^{1}$ \\
\hline \multirow{2}{*}{ MG } & 1 & $<1,0 \times 10^{1}$ & $6,0 \times 10^{3}$ & $<3,0$ & $<3,0$ & $>1,0 \times 10^{4}$ \\
\hline & 2 & $<1,0 \times 10^{1}$ & $1,4 \times 10^{5}$ & $<3,0$ & $<3,0$ & $>1,0 \times 10^{4}$ \\
\hline \multirow{2}{*}{ MI } & 1 & $<1,0 \times 10^{1}$ & $<1,0 \times 10^{1}$ & $<3,0$ & $<3,0$ & $>1,0 \times 10^{4}$ \\
\hline & 2 & $<1,0 \times 10^{1}$ & $1,7 \times 10^{7}$ & $<3,0$ & $<3,0$ & $1,1 \times 10^{9}$ \\
\hline \multirow{2}{*}{$\mathbf{A A}$} & 1 & $<1,0 \times 10^{1}$ & $1,8 \times 10^{3}$ & $>1,0 \times 10^{4}$ & $4,3 \times 10^{1}$ & $>1,0 \times 10^{4}$ \\
\hline & 2 & $<1,0 \times 10^{1}$ & $4,5 \times 10^{4}$ & $1,1 \times 10^{3}$ & $<3,0$ & $1,2 \times 10^{6}$ \\
\hline \multirow{2}{*}{$\mathbf{A B}$} & 1 & $<1,0 \times 10^{1}$ & $<1,0 \times 10^{1}$ & $<3,0$ & $<3,0$ & $>1,0 \times 10^{4}$ \\
\hline & 2 & $<1,0 \times 10^{1}$ & $1,1 \times 10^{5}$ & $3,5 \times 10^{1}$ & $<3,0$ & $<1,0 \times 10^{1}$ \\
\hline \multirow{2}{*}{$\mathbf{A C}$} & 1 & $<1,0 \times 10^{1}$ & $1,7 \times 10^{4}$ & $<3,0$ & $<3,0$ & $<1,0 \times 10^{1}$ \\
\hline & 2 & $<1,0 \times 10^{1}$ & $<1,0 \times 10^{1}$ & $<3,0$ & $<3,0$ & $<1,0 \times 10^{1}$ \\
\hline \multirow{2}{*}{ AG } & 1 & $<1,0 \times 10^{1}$ & $<1,0 \times 10^{1}$ & $<3,0$ & $<3,0$ & $<1,0 \times 10^{1}$ \\
\hline & 2 & $<1,0 \times 10^{1}$ & $>1,0 \times 10^{4}$ & $<3,0$ & $<3,0$ & $2,1 \times 10^{6}$ \\
\hline \multirow{2}{*}{ AI } & 1 & $<1,0 \times 10^{1}$ & $<1,0 \times 10^{1}$ & $<3,0$ & $<3,0$ & $>1,0 \times 10^{4}$ \\
\hline & 2 & $<1,0 \times 10^{1}$ & $>1,0 \times 10^{4}$ & $<3,0$ & $<3,0$ & $>1,0 \times 10^{4}$ \\
\hline \multirow{2}{*}{ PC } & 1 & $<1,0 \times 10^{1}$ & $8,2 \times 10^{2}$ & $<3,0$ & $<3,0$ & $<1,0 \times 10^{1}$ \\
\hline & 2 & $<1,0 \times 10^{1}$ & $<1,0 \times 10^{1}$ & $<3,0$ & $<3,0$ & $>1,0 \times 10^{4}$ \\
\hline \multirow{2}{*}{ PG } & 1 & $<1,0 \times 10^{1}$ & $>1,0 \times 10^{4}$ & $<3,0$ & $<3,0$ & $2,1 \times 10^{4}$ \\
\hline & 2 & $<1,0 \times 10^{1}$ & $>1,0 \times 10^{4}$ & $<3,0$ & $<3,0$ & $>1,0 \times 10^{4}$ \\
\hline \multirow{2}{*}{ PI } & 1 & $<1,0 \times 10^{1}$ & $<1,0 \times 10^{1}$ & $<3,0$ & $<3,0$ & $>1,0 \times 10^{4}$ \\
\hline & 2 & $<1,0 \times 10^{1}$ & $2,0 \times 10^{5}$ & $<3,0$ & $<3,0$ & $>1,0 \times 10^{4}$ \\
\hline Padrão $^{3}$ & & $\begin{array}{l}\text { Padrão não } \\
\text { estabelecido }\end{array}$ & Máx. de 2,0x10 & Máx. de $10^{2}$ & Máx. de $10^{1}$ & Mín. $10^{7}$ \\
\hline
\end{tabular}

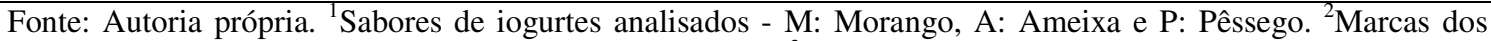
produtos - identificação da agroindústria (A, B, C, G e I). ${ }^{3}$ Refere-se ao padrão da legislação (BRASIL, 2007). UFC: Unidade Formadora de Colônias. NMP: Número Mais Provável.

Silva et al. (2012) ao analisar cinco diferentes marcas de iogurtes produzidas de forma industrial e caseira encontraram para uma amostra caseira resultado de coliformes a $45{ }^{\circ} \mathrm{C}>10 \mathrm{NMP} / \mathrm{g}$, estando em desacordo com o limite proposto pela legislação brasileira vigente (BRASIL, 2001; BRASIL, 2007). Já Emiliano et al. (2017) ao analisar sete diferentes marcas de iogurtes comerciais encontraram para todas as amostras valores de coliformes a $30{ }^{\circ} \mathrm{C}$ e a $45^{\circ} \mathrm{C}$ em conformidade com os limites preconizados. Esses resultados demostram a importância das Boas Práticas de Fabricação utilizadas dentro de uma unidade fabril para a produção de alimentos aptos ao consumo. $\mathrm{O}$ crescimento de coliformes em iogurtes é 
limitada pelos baixos valores de $\mathrm{pH}$, segundo Franco e Landgraf (2003), no geral, o número elevado de coliformes em alimentos processados indica processamento inadequado ou recontaminação pós-processamento.

Para as bactérias láticas a Instrução Normativa $\mathrm{n}^{\circ}$ 46/2007 (BRASIL, 2007) estabelece mínimo de contagem de $10^{7}$ UFC/g. Portanto, dentre as amostras de iogurte analisadas, apenas MI (lote 2) apresentou valor desejável $\left(1,1 \times 10^{9}\right.$ UFC/g) (Tabela 3). Emiliano et al. (2017) ao analisar sete diferentes marcas de iogurtes comerciais encontrou resultado acima de $10^{7} \mathrm{UFC} / \mathrm{g}$ apenas para uma amostra, o que indica, assim como no presente estudo, o alto índice de produtos em desacordo com o preconizado pelo Regulamento Técnico de Identidade e Qualidade de Leites Fermentados, Instrução Normativa $\mathrm{n}^{\circ} 46$ (BRASIL, 2007). Uma das principais funções da adição de bactérias láticas nos alimentos é a acidificação destes produtos pela transformação da lactose em majoritariamente ácido láctico, reduzindo a possibilidade de desenvolvimento de bactérias deteriorantes ou patogênicas. Além disso, as bactérias lácticas são responsáveis por outras transformações bioquímicas podendo envolver lipídios e proteínas, o que contribui para as propriedades sensoriais dos produtos fermentados.

$\mathrm{Na}$ análise microbiológica dos queijos (Tabela 4), pode-se observar que para a contagem de bactérias psicrotróficas, com exceção das amostras de queijos Minas Padrão das marcas D (PD) e G (PG), lote 1, e da amostra de queijo muçarela da marca $\mathrm{G}$ (MG), lote 2 , todas as demais amostras, apresentaram contagem superior a 3 ciclos $\mathrm{Log}$ $\left(>1,0 \times 10^{3}\right.$ UFC/g). Sangaletti et al. (2009) relataram contagens de bactérias psicrotróficas na ordem de 2,52 a 12,37 ciclos Log ao analisar queijos Minas Frescal entre $01^{\circ}$ e $\quad$ o $30^{\circ}$ dia de armazenamento. Melo et al. (2009) também encontraram valores elevados de bactérias psicotróficas $\left(8,3 \times 10^{3}\right.$ a $1,2 \times 10^{8}$ UFC/g) ao analisarem 30 amostras de queijos Minas Padrão comercializado na cidade de São Luís - MA. Os mesmos autores atribuem essa alta contagem de bactérias psicotróficas ao longo período de refrigeração no qual os queijos permanecem antes de serem oferecidos para consumo. Geralmente, o alto número de bactérias psicrotróficas reflete uma quantidade suficiente de proteases e lipases para causarem a quebra das proteínas e gordura (BARBANO et al. 2006), alterando as características sensoriais dos queijos de forma perceptível, limitando sua vida útil.

Para a contagem de fungos filamentosos e leveduras (Tabela 4), somente as amostras de queijos Minas Padrão das marcas $\mathrm{G}$ (PG, lote 2) e H (PH, lote 1), e os queijos muçarela das marcas $F$ (MF) e G (MG), ambas do lote 1, apresentaram contagem inferior a 4 ciclos $\log \left(1,0 \times 10^{4} \mathrm{UFC} / \mathrm{g}\right)$. As amostras de queijos mais contaminadas $\mathrm{PB}$ e ME (lote 1) e PA, PB e $\mathrm{PH}$ (lote 2) obtiveram contagem superior a 5 ciclos $\log \left(1,0 \times 10^{5}\right.$ UFC/g). Segundo a Portaria n. ${ }^{\circ}$ 146/1996 (BRASIL, 1996) queijos com umidade $>55 \%$ podem apresentar no máximo $5,0 \times 10^{3}$ UFC/g (3,70 ciclos Log), estando, portanto, todas as amostras de queijo Minas Frescal, do presente estudo, em desacordo com o estabelecido pelo seu Regulamento Técnico (BRASIL, 1996). Jahn et al. (2017) detectaram a presença de fungos filamentosos em 96,67\% das amostras de queijo tropical em diferentes fases de produção em uma indústria, também foi detectada a presença de fungos filamentosos no ar do ambiente da indústria, e nos utensílios. Peixoto et al. (2012) avaliaram amostras de leite, queijos, superfícies e placas expostas ao ar em quatro laticínios no Agreste Paraibano e observaram que os níveis de contaminação nas amostras de queijos foram superiores aos níveis de 
contaminação nas amostras de leites. Os autores constataram que isso se deve, provavelmente, à contaminação no ambiente de produção dos queijos, que pode ser por falta de higiene nos utensílios, da água, das pessoas que trabalham na fábrica, do local não adequado para conservação do queijo e também pela deficiência na estrutura nas instalações. Essa constatação possivelmente pode ser ampliada para o presente estudo.

Para coliformes a $30 \quad{ }^{\circ} \mathrm{C} \quad \mathrm{e}$ coliformes a $45^{\circ} \mathrm{C}$, a legislação brasileira permite um máximo de $10^{3}, 5 \times 10^{3}, 10^{4}$ ou $10^{5} \mathrm{NMP} / \mathrm{g}$ (BRASIL, 1996), e máximo de $5 \times 10^{2}, 10^{3}$ ou $5 \times 10^{3} \mathrm{NMP} / \mathrm{g}$ (BRASIL, 2001), respectivamente, dependendo das características do queijo. As amostras de queijo Minas Frescal FA (lote 1) e FG (lote 2 ), por terem sido caracterizadas como um queijo com alto teor de umidade ( $>55 \%)$, foram as únicas que se encontravam em desacordo com os padrões de qualidade preconizados pela Portaria n. ${ }^{\circ}$ 146/1996 (BRASIL, 1996), por apresentarem valores de coliformes a $30^{\circ} \mathrm{C}>10^{3}$ (3 ciclos Log), não estando aptas para o consumo. Todas as amostras de queijos analisadas estavam nos limites estabelecidos para coliformes a $45{ }^{\circ} \mathrm{C}$ (BRASIL, 2001) (Tabela 4). Resultado semelhante foi obtido por Castro et al. (2012) ao analisar coliformes a $45^{\circ} \mathrm{C}$ em muçarela comercializada no Ceasa de Vitória da Conquista - BA, onde $100 \%$ das amostras $(n=12)$ não estavam conforme o estabelecido pela legislação em vigor. Já na pesquisa de Dias et al. (2016), que avaliaram 10 amostras de queijo Minas Frescal artesanal e industrial, $70 \%$ e $100 \%$ das amostras foram condenadas por elevada contagem de coliformes totais $\left(1,1 \times 10^{4}\right.$ a $\left.>1,1 \times 10^{5}\right)$ e coliformes termotolerantes $\left(2,1 \times 10^{4}\right.$ a $\left.>1,1 \times 10^{5}\right)$, respectivamente, conforme $\mathrm{o}$ padrão estabelecido pela legislação vigente (BRASIL, 1996; BRASIL, 2001). Os supracitados autores atribuíram essa elevada contaminação a baixa qualidade do leite utilizado, a possível não pasteurização do leite utilizado no processo artesanal, e a possível recontaminação do leite após a pasteurização no processo industrial, devido à manipulação excessiva realizada por pessoas sem nenhum conhecimento e, ou cuidado de higiene.

Tabela 4: Média e desvio-padrão dos resultados das análises microbiológicas de queijos comercializados no município de Venda Nova do Imigrante - ES

\begin{tabular}{|c|c|c|c|c|c|c|}
\hline \multirow[b]{2}{*}{$\begin{array}{l}\text { Produto }^{1} / \\
\text { marca }^{2}\end{array}$} & \multirow[b]{2}{*}{ Lote } & \multicolumn{5}{|c|}{ Contagem microbiana } \\
\hline & & $\begin{array}{l}\text { Psicrotróficos } \\
\text { (UFC/g) }\end{array}$ & $\begin{array}{l}\text { Fungos filamentosos } \\
\text { e leveduras (UFC/g) }\end{array}$ & $\begin{array}{c}\text { Coliformes } \\
\text { a } 30^{\circ} \mathrm{C}(\mathrm{NMP} / \mathrm{g})\end{array}$ & $\begin{array}{c}\text { Coliformes } \\
\text { a } 45^{\circ} \mathrm{C}(\mathrm{NMP} / \mathrm{g})\end{array}$ & $\begin{array}{c}\text { Estafilococos } \\
\text { coag. positiva } \\
\text { (UFC/g) }\end{array}$ \\
\hline \multirow[b]{2}{*}{ FA } & 1 & $>1,0 \times 10^{4}$ & $>1,0 \times 10^{4}$ & $>1,1 \times 10^{3}$ & $>9,4$ & $4,3 \times 10^{2}$ \\
\hline & 2 & * & * & * & * & * \\
\hline \multirow{2}{*}{ FC } & 1 & $>1,0 \times 10^{4}$ & $>1,0 \times 10^{4}$ & $6,4 \times 10^{1}$ & $* *$ & $>1,0 \times 10^{4}$ \\
\hline & 2 & $2,5 \times 10^{7}$ & $>1,0 \times 10^{4}$ & $1,1 \times 10^{3}$ & $2,0 \times 10^{1}$ & $8,0 \times 10^{5}$ \\
\hline \multirow{2}{*}{ FG } & 1 & $>1,0 \times 10^{4}$ & $>1,0 \times 10^{4}$ & $3,5 \times 10^{1}$ & $* *$ & $2,5 \times 10^{5}$ \\
\hline & 2 & $>1,0 \times 10^{4}$ & $>1,0 \times 10^{4}$ & $>1,1 \times 10^{3}$ & $3,6 \times 10^{1}$ & $4,6 \times 10^{6}$ \\
\hline \multirow{2}{*}{ PA } & 1 & $6,6 \times 10^{5}$ & $8,6 \times 10^{4}$ & $1,5 \times 10^{2}$ & $1,5 \times 10^{1}$ & $<1,0 \times 10^{1}$ \\
\hline & 2 & $9,2 \times 10^{5}$ & $1,1 \times 10^{6}$ & $2,1 \times 10^{1}$ & 3,0 & $<1,0 \times 10^{1}$ \\
\hline \multirow{2}{*}{ PB } & 1 & $1,4 \times 10^{6}$ & $2,0 \times 10^{5}$ & 6,2 & $<3,0$ & $<1,0 \times 10^{1}$ \\
\hline & 2 & $2,1 \times 10^{6}$ & $7,5 \times 10^{5}$ & $<3,0$ & $<3,0$ & $2,7 \times 10^{6}$ \\
\hline PD & 1 & $<1,0 \times 10^{1}$ & $>1,0 \times 10^{4}$ & 3,0 & $<3,0$ & $* *$ \\
\hline
\end{tabular}




\begin{tabular}{|c|c|c|c|c|c|c|}
\hline & 2 & $>1,0 \times 10^{4}$ & $>1,0 \times 10^{4}$ & $<3,0$ & $<3,0$ & $4,5 \times 10^{4}$ \\
\hline \multirow{2}{*}{ PG } & 1 & $>1,0 \times 10^{1}$ & $>1,0 \times 10^{4}$ & $<3,0$ & $<3,0$ & $<1,0 \times 10^{1}$ \\
\hline & 2 & $>1,0 \times 10^{4}$ & $<1,0 \times 10^{1}$ & $<3,0$ & $<3,0$ & $<1,0 \times 10^{1}$ \\
\hline \multirow{2}{*}{$\mathbf{P H}$} & 1 & $5,0 \times 10^{5}$ & $<1,0 \times 10^{1}$ & $2,9 \times 10^{1}$ & $<3,0$ & $<1,0 \times 10^{1}$ \\
\hline & 2 & $* *$ & $6,5 \times 10^{5}$ & $1,1 \times 10^{1}$ & 3,0 & $<1,0 \times 10^{1}$ \\
\hline \multirow{2}{*}{ ME } & 1 & $3,0 \times 10^{4}$ & $6,4 \times 10^{5}$ & $7,5 \times 10^{1}$ & $<3,0$ & $<1,0 \times 10^{1}$ \\
\hline & 2 & $4,1 \times 10^{6}$ & $>1,0 \times 10^{4}$ & $3,6 \times 10^{1}$ & 7,2 & $4,5 \times 10^{4}$ \\
\hline \multirow{2}{*}{ MF } & 1 & $1,7 \times 10^{3}$ & $>1,0 \times 10^{4}$ & $3,6 \times 10^{1}$ & $<3,0$ & $2,6 \times 10^{3}$ \\
\hline & 2 & $2,7 \times 10^{5}$ & $<1,0 \times 10^{1}$ & $1,5 \times 10^{1}$ & 3,0 & $<1,0 \times 10^{1}$ \\
\hline \multirow{2}{*}{ MG } & 1 & $4,3 \times 10^{3}$ & $1,0 \times 10^{4}$ & 6,1 & $<3,0$ & $<1,0 \times 10^{1}$ \\
\hline & 2 & $<1,0 \times 10^{1}$ & $<1,0 \times 10^{1}$ & 7,2 & $<3,0$ & $<1,0 \times 10^{1}$ \\
\hline Padrão $^{3}$ & & $\begin{array}{c}\text { Padrão não } \\
\text { estabelecido }\end{array}$ & $\begin{array}{c}\text { Máx. de } 5 \times 10^{3} \\
\text { dependendo das } \\
\text { características do } \\
\text { queijo }\end{array}$ & $\begin{array}{c}\text { Máx. de } 10^{3}, 5 \times 10^{3}, \\
10^{4} \text { ou } 10^{5} \\
\text { dependendo das } \\
\text { características do } \\
\text { queijo }\end{array}$ & $\begin{array}{c}\text { Máx. de } 5 \times 10^{2}, 10^{3} \text {, } \\
\text { ou } 5 \times 10^{3} \\
\text { dependendo das } \\
\text { características do } \\
\text { queijo }\end{array}$ & $\begin{array}{c}\text { Máx. de } 5 \times 10^{2} \\
\text { ou } 10^{3} \\
\text { dependendo das } \\
\text { características do } \\
\text { queijo }\end{array}$ \\
\hline
\end{tabular}

Fonte: Autoria própria. ${ }^{1}$ Tipos de queijos analisados - F: Minas Frescal, P: Minas Padrão, M: Muçarela. ${ }^{2}$ Marcas dos produtos - identificação da agroindústria (A, B, C, D, E, F, G e H). ${ }^{3}$ Refere-se ao padrão da legislação (BRASIL, 1996; BRASIL, 2001; BRASIL, 2018). UFC: Unidade Formadora de Colônias. NMP: Número Mais Provável. "Repetição não realizada devido à falta de amostra no mercado local do munícipio de Venda Nova do Imigrante - ES. ${ }^{* *}$ Erro de análise.

Para a análise de estafilococos coagulase positiva a Resolução RDC n. ${ }^{\circ}$ 12/2001 (BRASIL, 2001) estabelece máximo de contagem de $5 \times 10^{2}$ ou $10^{3}$ $\mathrm{UFC} / \mathrm{g}$, dependendo das características do queijo. Das amostras de queijos analisadas no presente estudo, produtos de cinco marcas (B, C, D, E e G) estavam impróprias ao consumo com contagem de estafilococos coagulase positiva variando entre $>1,0 \times 10^{4} \mathrm{UFC} / \mathrm{g}$ a $4,6 \times 10^{6} \mathrm{UFC} / \mathrm{g}$, limites acima do estabelecido pela Resolução RDC n. ${ }^{\circ} 12 / 2001$ (BRASIL, 2001) para as características dos queijos analisados (Tabela 4).

$\mathrm{Na}$ pesquisa de Carvalho et al. (2007), que avaliou 93 amostras de queijo Minas Frescal comercializados na cidade de Campinas - SP, 29\% (n=9) das amostras, fabricadas com adição de cultura láctea, foram condenadas por elevada contagem de coliformes a $45^{\circ} \mathrm{C}\left(>5 \times 10^{2}\right)$ e $12,9 \%(n=4)$ por contaminação excessiva de estafilococos coagulase positiva $\left(>10^{3}\right)$, conforme $\mathrm{o}$ padrão estabelecido pela legislação vigente (BRASIL, 2001). Maior contaminação por estafilococos coagulase positiva (Staphylococcus aureus), que a do presente estudo foi descrito por Dias et al. (2016) onde, 90\% ( $n=9)$ dos queijos Minas Frescal analisados estavam com contagens a cima do permitido pela Resolução RDC n. ${ }^{\circ}$ 12/2001 (BRASIL, 2001).

A ampla disseminação do Staphylococcus spp. no ambiente justifica a presença deste microrganismo nos alimentos, principalmente naqueles submetidos à intensa manipulação sem as devidas práticas higiênico-sanitárias. Dessa forma, o manuseio incorreto, possivelmente empregado na fabricação dos queijos, foi uma das principais causas de contaminação por estafilococos coagulase positiva no presente estudo.

\subsection{ANÁLISE DA ROTULAGEM}

Os resultados da avaliação da rotulagem das amostras de iogurtes $(n=13)$ e queijos $(n=11)$, adquiridos no comércio local de Venda Nova do Imigrante - ES, estão descritos na Figura 1. Os dados 
foram expressos como índice de conformidade com a legislação vigente $(\%)$.

Verificou-se que todas as amostras de iogurtes e queijos estudadas apresentaram informações quanto à denominação de venda, informação nutricional, instrução de armazenamento, identificação do lote e, ou data de fabricação e prazo de validade e indicação do n. ${ }^{\circ}$ de registro e serviço de inspeção (Figura 1), atendendo ao previsto nas Resoluções RDC ANVISA n. ${ }^{\circ}$ 360/2003 (BRASIL, 2003a), n. ${ }^{\circ}$ 359/2003 (BRASIL, 2003c), n. ${ }^{\circ}$ 259/2002 (BRASIL, 2002a) e na Instrução Normativa n. ${ }^{\circ}$ 22/2005 (BRASIL, 2005).

O número de lote torna possível identificar todos os dados de processo e matéria-prima utilizados para a fabricação do produto que está sendo adquirido (TAVARES et al., 2003), possibilitando tanto o consumidor quanto a indústria fabricante encontrar a origem de um problema e, ou inconformidade.

De acordo com a Resolução RDC ANVISA n. ${ }^{\circ}$ 360/2003 (BRASIL, 2003a), sempre que atendam as condições de quantidades significativas é obrigatório declarar no rótulo as seguintes informações nutricionais: valor energético, carboidratos, proteínas, gorduras totais, gorduras saturadas, gorduras trans, fibra alimentar e sódio. Para quantidades não significativas a informação nutricional será expressa como "zero" ou " 0 " ou "não contém". Deve ainda utilizar medida caseira da porção informada na tabela nutricional utilizando utensílios domésticos como copo, fatia, etc., bem como a informação nutricional complementar relativa à declaração facultativa de propriedades nutricionais. É permitida uma tolerância de $20 \%$ (inferior ou superior) nos valores informados no rótulo, caso seja maior, a empresa responsável deve manter a disposição os estudos que justifiquem tal variação (BRASIL, 2003a).
As instruções de armazenamento e as especificações de conteúdo líquido (massa ou volume) são informações necessárias para que o produto alimentício tenha as mesmas características no término do prazo de validade e para que o consumidor saiba exatamente a quantidade de produto que está adquirindo, evitando equívocos e permitindo a comparação com as demais marcas disponíveis. Vale destacar que todas as informações devem ser declaradas com letras legíveis e não induzir o consumidor ao engano. Apenas $38,5 \%$ e $45,5 \%$ das amostras de iogurte e queijo, respectivamente, continham informações legíveis conforme o preconizado pelo Decreto n. ${ }^{\circ}$ 986/1969 (BRASIL, 1969) e Resolução RDC ANVISA n. ${ }^{\circ}$ 259/2002 (BRASIL, 2002a) (Figura 1). Segundo a legislação, nos rótulos das embalagens de alimentos que exijam condições especiais para sua conservação deve ser incluída uma legenda com caracteres bem legíveis, indicando as precauções necessárias para manter suas características normais; devendo ser indicadas as temperaturas máximas e mínimas para a conservação do alimento e o tempo que o fabricante, produtor ou fracionador garante sua durabilidade nessas condições (BRASIL, 2002a; BRASIL, 2005).

A declaração correta dos aditivos constava em apenas $61,5 \%$ das amostras de iogurte. Nenhuma amostra de queijo apresentava tal informação conforme a legislação (BRASIL, 2002a). Os aditivos alimentares devem ser declarados fazendo parte da lista de ingredientes, sendo descrita a função principal ou fundamental do aditivo no alimento e seu nome completo ou seu número INS (Sistema Internacional de Numeração, Codex Alimentarius FAO/OMS), ou ambos. Quando houver mais de um aditivo alimentar com a mesma função, pode ser mencionado um em continuação ao outro, agrupando-os por função. Os aditivos alimentares devem ser declarados depois dos ingredientes (BRASIL, 2002a). 
A indicação da "presença ou ausência de glúten" conforme estabelecido na Lei n. ${ }^{\circ}$ 10.674/2003 (BRASIL, 2003b) constava em $100 \%$ das amostras de iogurte e $63,6 \%$ de queijo. Esta informação é de suma importância para as pessoas celíacas ou que por motivos pessoais, preferem evitar ou reduzir o consumo de glúten, portanto, é necessária a atuação constante do serviço de inspeção para garantir o direito do consumidor.

A maioria das amostras analisadas (Figura 1) apresentavam o nome do produtor ou a identificação de origem nos rótulos. Para a identificação da origem devem ser indicados no rótulo o nome (razão social) do fabricante ou produtor ou fracionador ou titular (proprietário) da marca, o endereço completo, o país de origem, o município e o número de registro ou código de identificação do estabelecimento fabricante junto ao órgão competente. Para essa identificação deve ser utilizada uma das expressões: "fabricado em...", "produto..." ou "indústria..." (BRASIL, 2002a).

Figura 1: Índice de conformidade dos produtos analisados (iogurtes sabores ameixa, morango e pêssego, e queijos tipo Minas Frescal, Minas Padrão e muçarela) de nove marcas

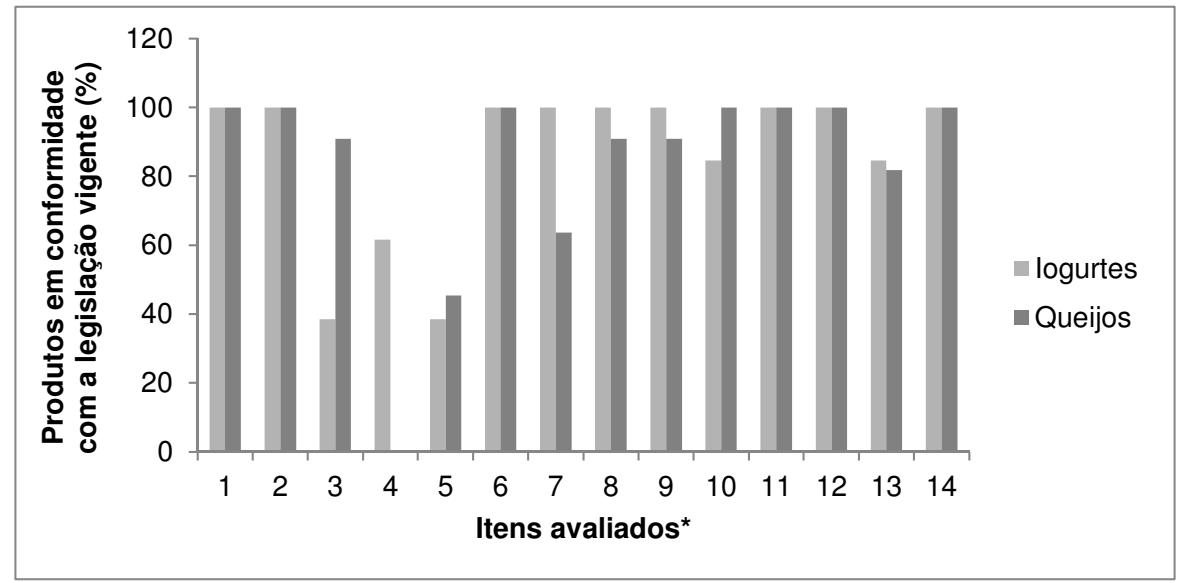

Fonte: Autoria própria. *Identificação dos itens avaliados: 1-Denominação de venda; 2-Informação nutricional; 3-Lista de ingredientes; 4-Aditivos; 5-Informações com caracteres legíveis; 6-Instrução de armazenamento; 7Presença ou ausência de glúten; 8-Conteúdo líquido; 9-Identificação do fabricante/produtor; 10-Identificação de origem; 11-Identificação do lote/data de fabricação; 12-Prazo de validade, 13-Serviço de Atendimento ao Consumidor e 14-Indicação do n. ${ }^{\circ}$ de registro e serviço de inspeção.

Quanto à presença da informação sobre Serviço de Atendimento ao Consumidor (SAC), verificou-se que em $84,6 \%$ e $81,8 \%$ dos rótulos, respectivamente de iogurtes e queijos, apresentaram essa informação, o que possibilita o consumidor esclarecer dúvidas sobre o produto que está adquirindo, caso necessário.

\section{CONCLUSÕES}

Os resultados das análises físicoquímicas e microbiológicas obtidos no presente trabalho revelam a presença de amostras (iogurte e queijo, de diferentes marcas) em desacordo com a legislação vigente para pelos um dos parâmetros analisados, indicando possíveis falhas no controle da qualidade e padronização desses produtos, indicando também procedimentos higiênicos inadequados durante a fabricação, manutenção em temperaturas inadequadas e uso de 
matéria-prima de baixa qualidade higiênico-sanitária.

Considerando-se os requisitos estabelecidos pela legislação brasileira para rotulagem, em geral, a maioria dos itens avaliados foi atendida pelos fabricantes das amostras de iogurtes e queijos estudadas. Vale destacar a necessidade de adequação quanto às informações corretas sobre aditivos e lista de ingredientes, e o uso de caracteres legíveis para todas as informações da rotulagem, já que estes itens apresentaram menor índice de conformidade dentre as amostras analisadas.

Os dados obtidos no presente estudo refletem a realidade de produtos lácteos analisados no período de 20142015, indicando a necessidade de uma constante e efetiva fiscalização da matériaprima, produto e rotulagem, para que alimentos em desacordo com a legislação não venham chegar ao mercado colocando em risco a saúde e os direitos do consumidor. Ressalta-se, portanto, a importância da realização de estudos futuros, como critério comparativo para avaliação da qualidade de produtos lácteos semelhantes aos analisados nesta pesquisa, visando identificar a situação atual dos produtos relacionada à qualidade e atendimento à legislação.

\section{AGRADECIMENTOS}

Os autores agradecem ao Instituto Federal do Espírito Santo, IFES, campus Venda Nova do Imigrante pelo suporte neste projeto.

\section{REFERÊNCIAS}

ABIA. Associação Brasileira das Indústrias da Alimentação. Números do setor:

Faturamento 2018. Disponível em: $<$ https://www.abia.org.br/vsn/anexos/fatur amento2018.pdf >. Acesso em: 17 abr. 2020.
ARRUDA, M. L. T. et al. Determinação de cloreto de sódio, nitrato e nitrito em queijos Minas Frescal e padrão comercializados em feiras livres de Goiânia - GO. Publicações em Medicina Veterinária e Zootecnia, v. 4, p. 1-10, 2010.

BARBANO, D. M.; MA, Y.; SANTOS, M. $\mathrm{V}$. Influence of raw milk quality on fluid milk shelf life. Journal of Dairy Science, v. 89, Suppl., p. 15-19, 2006.

BRASIL. Decreto Lei n. ${ }^{\circ}$ 986, de 21 de outubro de 1969. Institui Normas básicas sobre alimentos. Diário Oficial da União, Brasília, DF, 21 de out. de 1969.

BRASIL. Lei.$^{\circ}{ }^{8}$ 8.078, de 11 de setembro de 1990. Dispõe sobre a proteção do consumidor. Diário Oficial da União, 12 de set. de 1990.

BRASIL. Ministério da Agricultura. Portaria n. ${ }^{\circ}$ 146, de 07 de março de 1996. Aprova os Regulamentos Técnicos de Identidade e Qualidade dos Produtos Lácteos. Diário Oficial da União, 11 de mar. de 1996.

BRASIL. Ministério da Agricultura. Portaria n. ${ }^{\circ}$ 364, de 04 de setembro de 1997. Aprova o Regulamento Técnico para Fixação de Identidade e Qualidade de Queijo Mozzarella. Diário Oficial da União, Brasília, DF, 04 de set. de 1997.

BRASIL. Resolução RDC ANVISA n. ${ }^{\circ}$ 12, de 02 de janeiro de 2001. Aprova o Regulamento Técnico Sobre Padrões Microbiológicos Para Alimentos. Diário Oficial da União, Brasília, DF, 10 de jan. de 2001.

BRASIL. Resolução RDC ANVISA n. ${ }^{\circ}$ 259, de 20 de setembro de 2002. Aprovar o Regulamento Técnico sobre Rotulagem de Alimentos Embalados. Diário Oficial da União, Brasília, DF, 23 de set. de 2002a. 
BRASIL. Ministério do Desenvolvimento, Indústria e Comércio Exterior - MDIC. Portaria INMETRO n. ${ }^{\circ} 157$, de 19 de agosto de 2002. Aprova o Regulamento Técnico Metrológico estabelecendo a forma de expressar o conteúdo líquido a ser utilizado nos produtos pré-medidos. Diário Oficial da União, Brasília, DF, 20 de ago. de 2002b.

BRASIL. Resolução RDC ANVISA n. ${ }^{\circ}$ 360, de 23 de dezembro de 2003. Aprova o Regulamento Técnico sobre Rotulagem Nutricional de Alimentos Embalados. Diário Oficial da União, Brasília, DF, 26 de dez. de 2003a.

BRASIL. Lei n. ${ }^{\circ} 10.674$, de 16 de maio de 2003. Obriga a que os produtos alimentícios comercializados informem sobre a presença de glúten, como medida preventiva e de controle da doença celíaca. Diário Oficial da União,

Brasília, DF, 19 de maio de 2003b.

BRASIL. Resolução RDC ANVISA n. ${ }^{\circ}$ 359, de 23 de dezembro de 2003. Aprova o Regulamento Técnico de Porções de Alimentos Embalados para Fins de Rotulagem Nutricional. Diário Oficial da União, Brasília, DF, 26 de dez. de 2003c.

BRASIL. Ministério da Agricultura, Pecuária e Abastecimento. Instrução Normativa n. ${ }^{\circ}$ 4, de 01 de março de 2004. Altera a Portaria n 352 de 04/09/1997, Regulamento Técnico para Fixação de Identidade e Qualidade de Queijo Minas Frescal. Diário Oficial da União, Brasília, DF, 05 de mar. de 2004.

BRASIL. Ministério da Agricultura, Pecuária e Abastecimento. Instrução Normativa n. $^{\circ} 22$, de 24 de novembro de 2005. Aprovar o Regulamento Técnico para Rotulagem de Produto de Origem Animal Embalado. Diário Oficial da União, Brasília, DF, 25 de nov. de 2005.
BRASIL. Ministério da Agricultura, Pecuária e Abastecimento. Instrução Normativa n. ${ }^{\circ} 68$, de 12 de dezembro de 2006. Oficializa os Métodos Analíticos Oficiais Físico-Químicos, para Controle de Leite e Produtos Lácteos. Diário Oficial da União, Brasília, DF, 14 de dez. de 2006.

BRASIL. Ministério da Agricultura, Pecuária e Abastecimento. Instrução Normativa n. ${ }^{\circ} 46$, de 23 de outubro de 2007. Aprova o Regulamento Técnico de Identidade e Qualidade de Leites Fermentados. Diário Oficial da União, Brasília, DF, 11 de out. de 2007.

BRASIL. Ministério da Agricultura, Pecuária e Abastecimento. Portaria n. ${ }^{\circ} 837$, de 18 de junho de 2018. Altera a Portaria $\mathrm{N}^{\mathrm{o}} 364$, de 4 de setembro de 1997, Regulamento Técnico para Fixação de Identidade e Qualidade de Queijo Mozzarella. Diário Oficial da União, Brasília, DF, 20 de jun. de 2018.

CARVALHO, J. D. G.; VIOTTO, W. H.; KUAYE, A. Y. The quality of Minas Frescal cheese produced by diVerent technological processes. Food Control, v. 18, p. 262-267, 2007.

CASTRO, A. C. S.; PINTO JÚNIOR, W. R.; TAPIA, D. M. T.; CARDOSO, L. G. V. Avaliação da qualidade físico-química e microbiológica de queijos do tipo mussarela comercializados no Ceasa de Vitória da Conquista - BA. Alimentos e Nutrição, v. 23, p. 407-413, 2012.

CECCHI, H. M. Fundamentos teóricos e práticos em análise de alimentos. 2. ed. Campinas: Editora Unicamp, 2003. 207p.

CUNHA, C. R.; SPADOTI, L. M.; ZACARCHENCO, P. B.; VIOTTO, W. H. Efeito do fator de concentração do retentado o rendimento de queijo Minas Frescal de baixo teor de gordura fabricado 
por ultrafiltração. Ciência e Tecnologia de Alimentos, v. 22, p. 76-81, 2002.

DA SILVA, N.; JUNQUEIRA, V. C. A.; SILVEIRA, N. F. A.; TANIWAKI, M. H.; DOS SANTOS, R. F. S.; GOMES, R. A. $R$. Manual de métodos de análise microbiológica de alimentos e água. 4 . ed. São Paulo: Varela; 2010. 624 p.

DA SILVA, N. C.; TUNES, R. M. M.; CUNHA, M. F. Avaliação química de queijos Minas artesanais frescos e curados em Uberaba, MG. Publicações em Medicina Veterinária e Zootecnia, v. 6, p. 1-21, 2012.

DE SOUSA, A. Z. B.; ABRANTES, M. R.; SAKAMOTO, S. M.; DA SILVA, J. B. A.; LIMA, P. O.; DE LIMA, R. N.; ROCHA, M. O. C.; PASSOS, Y. D. B. Aspectos físico-químicos e microbiológicos do queijo tipo coalho comercializado em estados do nordeste do Brasil. Arquivos do Instituto Biológico, v. 81, n. 1, p. 30-35, 2014.

DE SOUZA, I. A.; GIOVANNETTI, A. C. S.; SANTOS, L. G. F.; GANDRA, S. O. S.; MARTINS, M. L.; RAMOS, A. L. S. Qualidade microbiológica de queijo Minas frescal comercializado na Zona da Mata Mineira. Revista do Instituto de Laticínios Cândido Tostes, v. 72, n. 3, p. 152-162, jul/set, 2017.

DIAS, B. F.; FERREIRA, S. M.; CARVALHO, V. S.; SOARES, D. S. B. Qualidade microbiológica e físico-química de queijo Minas Frescal artesanal e industrial. Revista de Agricultura Neotropical, v. 3, p. 57-64, 2016.

DOS SANTOS, G.; CUNHA, V. C. M.; PEDRAL, A. L.; DA SILVA, G. F.; DA SILVA, M. A. A. P.; PAGANI, A. A. C. Avaliação das características físicoquímicas do iogurte liofilizado e reidratado. In: VII International Symposium on Technological Innovation,
ISTI/SIMTEC, v. 3, n. 1, p. 723-728, 2016.

EMBRAPA. Empresa Brasileira de Pesquisa Agropecuária. O Mercado Consumidor de Leite e Derivados. Circular Técnica 120. 2019, 20p.

EMILIANO, J. V. S.; MOREIRA JÚNIOR, S.; MARTINS, F. O.; SILVA, C. R.; CAMPOS, R. C. A. B.; BALBI, P. V. T.; MARTINS, A. D. O. Avaliação físicoquímica e microbiológica de iogurtes comercializados em Rio Pomba/MG e comparação com os parâmetros da legislação. Vértices, v. 19, p. 191-200, 2017.

FERREIRA, M. L.; PALHARES, G. L.; SILVA, A. A.; SOUZA, S. M. O. Análise de psicrotróficos e psicrotróficos proteolíticos em iogurte integral. Publicações em Medicina Veterinária e Zootecnia, v. 13, p. 1-8, 2019.

FRANCO, B. D. G. M.; LANDGRAF, M. Microbiologia dos alimentos. São Paulo: Atheneu, 2003. 182p.

FUENTE, M. A.; MONTES, F.; GUERRERO, G.; JUÁREZ, M. Total and soluble contents of calcium, magnesium, phosphorus and zinc in yoghurts. Food Chemistry, v. 80, 2003, p. 573-578, 2003.

FURTADO, M. M. Quesos típicos de latinoamerica. São Paulo: Fonte Comunicações, 2005.192p.

GDP. Global Dairy Platform. Annual Review 2016. 2017. Disponível em: $<$ https://www.globaldairyplatform.com/wp -content/ uploads/2018/04/2016-annual-reviewfinal.pdf>. Acesso em: 17 abr. 2020.

IAL. Instituto Adolfo Lutz. Métodos Químicos e físicos para análise de alimentos. São Paulo: Instituto Adolfo Lutz, 2008. 1020 p. 
JAHN, R. C.; GARCIA, M. V.; COPETTI, M. V. Deterioração fúngica em indústria de queijo tipo tropical. Brazilian Journal of Food Research, v. 8, p. 16-25, 2017.

JAY, J. M. Microbiologia de Alimentos.

6, ed. Porto Alegre: Ed. Artmed, 2005. 712 p.

KLEIN, C. S.; FASSINA, P. Relação entre o consumo de alimentos funcionais e alterações fisiológicas em praticantes de atividade física. Caderno pedagógico, $v$. 12, p. 22-35, 2015.

LIMA, S. E. R.; MARTINS, W. F.; MELO, F. S. N.; SILVA, E. V.; ARAÚJO, A. S. Estudo do crescimento de bactérias psicrotróficas e mesófilas em iogurte enriquecido com grãos. Caderno Verde de Agroecologia e Desenvolvimento Sustentável, v. 4, 2014.

MARTINS, G. H.; KWIATKOWSKI, A.; BRACHT, L.; SRUTKOSKE, C. L. Q.; HAMINIUK, C. W. I. Perfil físicoquímico, sensorial e reológico de iogurte elaborado com extrato hidrossolúvel de soja e suplementado com inulina. Revista Brasileira de Produtos Agroindustriais, v. 15, p. 93-102, 2013.

MELO, A. C. M.; ALVES, L. M. C.; COSTA, F. N. Avaliação da qualidade microbiológica do queijo tipo Minas Padrão comercializado na cidade de São Luís, MA. Arquivos do Instituto Biológico, v. 76, p. 547-551, 2009.

MOREIRA, S.R.; SCHWAN, R.F.; CARVALHO, E.P. de; WHEALS, A.E. Isolation and identification of yeasts and filamentous fungi from yoghurts in Brazil. Brazilian Journal of Microbiology, v. 32, p. 117-122, 2001.

MUNHOZ, C. L.; HIRATA, V. G.; FRIA, S. B.; FERREIRA, T. H. B. Elaboração de iogurtes de açaí (Euterpe oleracea) com adição de prebióticos. Global Science and Technology, v.12, n. 3, p. 20-31, set/dez. 2019.

OLIVEIRA, F. M.; LYRA, I. N.; ESTEVES, G. S. G. Avaliação microbiológica e físico-química de iogurtes de morango industrializados e comercializados no município de Linhares - ES. Revista Brasileira de Produtos Agroindustriais, v. 15, p. 147-155, 2013.

PEIXOTO, J. P. N.; NASCIMENTO, J. W. B.; FURTADO, D. A.; OLIVEIRA, C. J. B.; GOMES, J. P. Qualidade do ambiente e níveis de contaminação por microorganismos em queijarias, no Agreste Paraibano. Revista Brasileira de Produtos Agroindustriais, v. 14, p. 177183, 2012.

RIBEIRO, L. R.; MATIAS, T. G.; MARTINS, E. M. F.; MARTINS, M. L.; MARTINS, A. D. O.; BITTENCOURT, F.; CAMPOS, R. C. A. B.

Desenvolvimento e caracterização de iogurte adicionado de geleiada da casca de jabuticaba e de cultura probiótica. Higiene Alimentar, v. 30, p. 136-141, 2016.

SANGALETTI, N.; PORTO, E.; BRAZACA, S. G. C.; YAGASAKI, C. A.; DALLA DEA, R. C.; SILVA, M. V.

Estudo da vida útil de queijo Minas. Ciência e Tecnologia de Alimentos, v. 29, p. 262-269, 2009.

SEBRAE. Serviço Brasileiro de Apoio às Micro e Pequenas Empresas. Técnicas e Boas Práticas na Produção de Queijo.

Resposta Técnica. 2014. 6p.

SILVA, L. C.; MACHADO, T. B.; SILVEIRA, M. L. R.; ROSA, C. S.; BERTAGNOLLI, S. M. M. Aspectos microbiológicos, $\mathrm{pH}$ e acidez de iogurtes de produção caseira comparados aos industrializados da região de Santa Maria RS. Disciplinarum Scientia, v. 13, p. 111120, 2012. 
TACO. Tabela Brasileira de Composição de Alimentos. 4. ed. Campinas: NEPAUNICAMP, 2011. 61 p.

TAVARES, L. B. B.; MACHADO, R.; BLEMER, R.; CARNEIRO, A. Avaliação das informações contidas nos rótulos das embalagens de geleias e doces sabores morango e tutti-fruti. Alimentos e Nutrição, v. 14, p. 27-33, 2003.
TEBALDI, V. M. R.; RESENDE, J. G. O. S.; RAMALHO, G. C. A.; OLIVEIRA, T. L. C.; ABREU, L. R.; PICCOLI, R. H. Avaliação microbiológica de bebidas lácteas fermentadas adquiridas no comércio varejista do sul de Minas Gerais. Ciência e Agrotecnologia, v. 31, p. 10851088, 2007. 